\title{
Deutsch im Diskurs der Illyrischen Bewegung (1835-1843): Bedrohung, Leitbild, Überbrückungsinstrument
}

\section{Einführung in den Forschungskontext: Gesellschaft und Sprache in der Zeit der Illyrischen Bewegung}

Die Illyrische Bewegung (1835-1843) kann als eine sprachliche, kulturelle und politische Initiative im Rahmen der Kroatischen Nationalen Wiedergeburt (1790-1848) bezeichnet werden. ${ }^{1}$ Historiographische Untersuchungen haben nachgewiesen, dass die Illyrische Bewegung nicht zuletzt aus einer tiefen Enttäuschung über die wirtschaftliche, gesellschaftliche und politische Lage der kroatischen Kronländer entstanden war. ${ }^{2}$ In der ersten Hälfte des 19. Jahrhunderts lebte noch mehr als $85 \%$ der Bevölkerung in Kroatien außerhalb städtischer Zentren, ${ }^{3} \mathrm{zu}$ verzeichnen war der gleiche Anteil an Analpha-

1 Der vorliegende Text basiert auf dem im Juni 2014 in Zadar auf dem Symposion zum Thema »Deutsche Sprache und Kultur in Kroatien " gehaltenen Vortrag Einstellungen gegenüber der deutschen Sprache in Kroatien in der ersten Hälfte des 19. Jhdts.

2 Vgl. Šidak et al.: Hrvatski narodni preporod; Stančić: Hrvatska nacija; Švoger: Zagrebački liberalni tisak.

3 Um 1840 hatten bspw. Zagreb und Osijek nur je 12.000 Einwohner, während Wien zur selben Zeit rund 400.000 Einwohner hatte (Stančić: Hrvatski narodni preporod). $\mathrm{Zu}$ detaillierteren demographischen Einschätzungen
Die Ideologie der Illyrischen

Bewegung brachte spezifische narrative Muster mit sprachideologischen Elementen hervor, die sich eng an die zeittypische These von der Untrennbarkeit von Sprache und Nation anlehnen. Dazu gehört die Schilderung des erwünschten patriotischen Verhaltens zur Förderung der Nationalsprache. Die Verwendung von Fremdsprachen sowohl in der öffentlichen als auch in der privaten Sphäre wird als unverantwortlich und für die Nationalsprache bedrohend geschildert, so dass im Diskurs vorwiegend negative Einstellungen gegenüber der deutschen Sprache zu verzeichnen sind. Andererseits zeigt die Diskursanalyse, dass Deutsch, die dominante Konversationssprache höherer Schichten, für die Illyristen als Überbrückungssprache, aber auch als Medium für Aktivismus unumgänglich war. 
beten. ${ }^{4}$ Es existierte keine bedeutendere Kapitalakkumulation, weswegen sich auch Industrialisierung und Modernisierung der Agrarwirtschaft nur langsam fortentwickelten. Von einem lahmenden Fortschritt gegenüber dem Rest der Monarchie zeugt u.a. auch die späte Einführung der Dampfkraft (1835, fast dreißig Jahre nach der ersten Dampfmaschine in der Monarchie $)^{5}$ und das späte Ende der feudalen Verhältnisse in Kroatien (1848, als eine der letzten Regionen im damaligen Europa).

Die genannten Umstände sowie die Unzufriedenheit mit der politischen Lage der kroatischen Kronländer in Bezug auf Ungarn, führten zu immer stärkeren Bestrebungen in Richtung der Vereinigung kroatischer Länder innerhalb der Monarchie, der Verteidigung kroatischer Munizipalrechte bzw. größerer Autonomie von Zivilkroatien und Zivilslawonien gegenüber Ungarn, wie auch in Richtung eines engeren kulturellen Bündnisses mit anderen südslawischen Völkern. Der kroatische Adel und das Bürgertum erhofften dadurch einen slawischen politischen Gegenpart im Sinne des Trialismus und Austroslawismus erzeugen zu können. ${ }^{6}$ Wenn man die gleichzeitige Stärkung anderer, slawischer wie auch nicht-slawischer, Nationalismen in Europa in Betracht zieht, wird ersichtlich, dass die Verhältnisse für die Entstehung und Stärkung der kroatischen nationalen Bewegung durchaus förderlich waren. Mitglieder der Illyrischen Bewegung und Anführer anderer slawischer Nationalbewegungen in der Monarchie standen in intensivem Briefwechsel und unterstützten sich gegenseitig.?

Obwohl die Illyristen wiederholt von einer breiten nationalen Resonanz berichteten, schätzt man heute, dass ungefähr 600 Personen auf unterschiedliche Weise in der Bewegung mitgewirkt haben, ${ }^{8}$ und zwar fast ausschließlich in städtischen Zentren im nordwestlichen Kroatien (Zagreb, Varaždin, Križevci, Karlovac, Sisak). Ob man hierbei tatsächlich von einem breiten nationalen Aufschwung sprechen kann, ist zu bezweifeln. Der Bewegung gelang es aber zweifellos innerhalb von zehn Jahren, den entscheidenden in erster Linie sprachlichen und institutionellen - Aufschwung zu erzielen. ${ }^{9}$ Auf der anderen Seite war die Bewegung eine sozial und ethnisch heterogene

kroatischer Kronländer in der Zeit der sog. nationalen Wiedergeburt s. Kessler: Politik, Kultur und Gesellschaft, S. 117-133.

4 Škiljan: Govor nacije, S. 241.

5 Vgl. Stančić: Hrvatski narodni preporod.

6 Zum Trialismus und Austroslawismus in der illyristischen Ideologie s. Korunić: Rasprava; Markus: Bogoslav Šulek.

7 Vgl. Barac: Hrvatska književnost, S. 123.

8 Ebd., S. 139

9 Vgl. Gross: O integraciji, S. 183; Novak: Po rodu, po karvi, S. 150. 
Gruppe. Unter den Mitwirkenden waren sowohl Vertreter des Bürgertums, als auch Adlige, Studenten, Mitglieder des progressiveren katholischen Klerus und des Militärs. Am zahlreichsten vertreten waren zwar Kroaten, es gab aber auch viele Mitglieder serbischer, slowenischer, slowakischer, österreichischer, deutscher, griechischer und französischer Herkunft. ${ }^{10}$

Der Name der Bewegung zeugt von einem angestrebten Integrationsrahmen, der nicht nur die kroatischen Kronländer umfasste. Der illyrische Name erfreute sich (wenn auch in veränderlichen Konzeptionen) einer langanhaltenden Tradition auf dem Gebiet des westlichen Balkans, ${ }^{11}$ überdies war er geeigneter als der Begriff/Terminus `kroatisch`, der zu dieser Zeit lediglich Zivilkroatien bzw. den Nordwesten Kroatiens bezeichnete. ${ }^{12}$ Die Bewegung zielte ursprünglich auf die Vereinigung aller Teile Kroatiens, in den frühen Phasen allerdings auch auf die kulturelle Vereinigung aller südslawischen Völker im Rahmen einer Literatursprache. Die Bezeichnung >illyrisch ‘ war in diesem Sinne wohl zugleich inhaltsoffen und legitim genug, um eventuelle Widerstände zu vermeiden. ${ }^{13}$

Nicht zuletzt aufgrund der bereits erwähnten intensiven Kommunikation zwischen den Mitgliedern verschiedener sog. nationaler Wiedergeburtsbewegungen in der Monarchie korrespondieren Hauptziele bzw. Etappen der Illyrischen Bewegung mit jenen bei anderen sich konstituierenden mitteleuropäischen Nationen. ${ }^{14}$ Es geht um die folgenden Etappen: 1. Kodifizierung einer überregionalen Nationalsprache; 2. Institutionalisierung der Nationalsprache (vor allem in Politik und Schulwesen); 3. Gründung von kulturellen, wissenschaftlichen und wirtschaftlichen Institutionen; 4. Gründung von politischen Institutionen (z.B. Illyrische Volkspartei, 1841); 5. politische Vereinigung kroatischer Kronländer und kulturelle Vereinigung mit anderen südslawischen Nationen innerhalb der Monarchie als Meilenstein auf dem Weg zu einem trialistischen bzw. austroslawistischen Aufbau

10 Mehrere bekannte Mitglieder der Bewegung kroatisierten ihre Vor- und Nachnamen. Der Komponist Ignatius Fuchs änderte bspw. seinen Namen auch amtlich zu Vatroslav Lisinski (Šrepel: Molba V. Lisinskoga, S. 216-217).

11 Die Auffassung, die südslawischen Völker seien Nachkommen der antiken Illyrier, teilten allerdings nur wenige Mitglieder der Illyrischen Bewegung. Dragutin Rakovac schreibt in seiner zweisprachig veröffentlichten polemischen Schrift aus dem Jahre 1842 Mali katekizam za velike ljude/Kleiner Katechismus fuer grosse Leute, ein Beweis gegen das Slawentum der antiken Illyrier sei nicht erbracht worden; doch sei diese Frage auch irrelevant, da die Illyristen den illyrischen Namen als vereinigende Bezeichnung für alle südslawischen Völker in der Gegenwart auffassen. Der Text dieser programmatischen Schrift ist zugänglich in: Šicel: Programski spisi, S. 125-138, hier S. 131.

12 Tafra: Značenje narodnoga preporoda, S. 45.

13 Blažević: Ilirizam prije ilirizma.

14 Über die allgemeinen Ziele von Nationalbewegungen, insbesondere der Illyrischen Bewegung siehe: Gross: O integraciji; Korunić: Rasprava. 
der Monarchie. Man kann schließen, dass eine entstehende politische Elite auf nationalistischer Plattform nach politischer Relevanz im spätfeudalen System strebte, um einen eigenen politischen Standpunkt gegenüber Wien und Ofen-Pest einnehmen zu können.

In der ersten Phase befassten sich die Illyristen primär mit Spracharbeit. ${ }^{15}$ Es gibt zweierlei Gründe für eine solche Schwerpunktwahl: Erstens wurde die Sprache von den Illyristen als Medium für die Verbreitung von gruppenspezifischem Wissen und Wertesystemen betrachtet. Wie in der Analyse deutlich wird, finden sich bei ihnen häufig Äußerungen über die Notwendigkeit, allen sozialen Schichten Bildung in der Muttersprache zugänglich zu machen. Dabei werden Deutsch, Latein und Ungarisch als Ressourcen erwähnt, die nicht allen Gesellschaftsschichten gleich zugänglich waren und somit als Instrumente der Macht und Kontrolle fungierten. Zweitens erforderte die Spracharbeit keine fortgeschrittene Infrastruktur. Der Illyrischen Bewegung genügte eine kleine Gruppe von Enthusiasten mit klassischer Bildung und eine Druckerei mit kaiserlicher Betriebsgenehmigung.

Grammatiken, orthographische Werke und Wörterbücher wurden gedruckt, Zeitungen mit Originaltexten in der Nationalsprache herausgegeben, programmatische Texte über die Notwendigkeit des Erlernens und der Anwendung der Nationalsprache verfasst. Außer der Entwicklung der Nationalsprache unternahmen Illyristen auch gezielte Aktionen zur Förderung der Sprachidentität: Das eigene sprachliche Handeln sollte zeigen, dass die Nationalsprache in allen Bereichen genauso gut verwendet werden kann wie Latein und Deutsch. ${ }^{16}$ Sprachgeschichtlich gesehen gelang den Illyristen ein entscheidender Aufschwung in der Stärkung der neuen štokavischen Literatursprache in den öffentlichen Bereichen, die der Nationalsprache früher verwehrt waren (Politik, Bildung). Es begannen Prozesse mit weitreichenden Auswirkungen nicht nur auf das politische und kulturelle Leben, sondern

15 Spracharbeit wird hier im breitesten Sinne als Gemeinsamkeit aller Aktivitäten verstanden, die auf die Sprachplanung (u.a. Kodifizierung) und Förderung einer Sprache gerichtet sind. Wie wichtig Spracharbeit für die Illyristen war, zeugt unter anderem die folgende Reflexion des Anführers Ljudevit Gaj drei Jahrzehnte nach dem Auftakt der Bewegung: »Es war unsere Nationalität, und mit dieser unsere Volkssprache; unsere Nationalität, die aus dem Kampfe siegreich hervorging und zum erstenmal am europäischen Horizont glänzend aufleuchtet, und unsere Sprache, die zum erstenmale ihren Siegesruf der Welt verkündete. (Aus: Gedanken zum Ausgleich Croatiens und Slawoniens mit der Regierung, 1864).

16 Ein bezeichnendes Beispiel ist die erste kroatische Rede im Sabor, dem kroatischen Parlament. Obwohl die verbindliche Amtssprache 1843 noch immer Latein war, hielt der Abgeordnete Ivan Kukuljević Sakcinski, ein junger Adliger aus den Reihen der Illyrischen Bewegung, eine Rede über die Notwendigkeit der Förderung der Nationalsprache auf Kroatisch (Transkript der Rede zugänglich in: Šicel: Programski spisi, S. 151-167). Kroatisch wurde erst 1847 als Amtssprache im Sabor eingeführt. 
auch auf die Stärkung der kroatischen Sprache, langfristig auf Kosten der deutschen Sprache sowie anderer Sprachen in Kroatien. ${ }^{17}$

Dabei war die Situation im soziolinguistischen Sinne eher ungünstig für die Förderung einer neuen Literatursprache auf štokavischer Grundlage. Einerseits war in der ersten Hälfte des 19. Jahrhunderts Deutsch am Höhepunkt seiner Dominanz im nordwestlichen Kroatien, ${ }^{18}$ andererseits gab es weitere Sprachkonkurrenzen auf diesem Gebiet. ${ }^{19}$ Die organischen Idiome im nordwestlichen Kroatien sind kajkavisch, dazu kommt auch eine jahrhundertelange literatursprachliche kajkavische Tradition. Die kajkavische Literatursprache war in der Wiedergeburtszeit im fortgeschrittenen Stadium der Kodifizierung und Standardisierung. ${ }^{20}$ Die Polyfunktionalität der damaligen kajkavischen Literatursprache äußert sich in der Veröffentlichung von Lehrbüchern, administrativen Texten, juristischer Literatur, literarischen Übersetzungen, religiöser Literatur und anderen Textsorten. Die Illyristen entschieden sich dennoch für Štokavisch als Grundlage der neuen, vereinigenden Literatursprache. Vom Štokavischen erhofften sie sich ein breiteres Anwendungsgebiet, ${ }^{21}$ da organische Idiome dieser Sprache sowohl in Slawonien, als auch im südlichen Kroatien, dem Großteil von Bosnien und Serbien existier(t)en. Ihre Entscheidung rechtfertigten die Illyristen unter anderem auch mit dem Hinweis auf kanonisierte štokavische literarische Vorbilder, vor allem der Dubrovniker Literaten des 16. und 17. Jahrhunderts und der bosnischen Franziskaner aus dem frühen 18. Jahrhundert. ${ }^{22}$ Außer dem Deutschen, der autochthonen kajkavischen Literatursprache und der entstehenden štokavischen überregionalen Literatursprache waren auch Ungarisch und Latein stark präsent. Latein war bis 1847 verbindliche Sprache in Politik und Verwaltung ${ }^{23}$ sowie Unterrichtssprache in Gymnasien bis 1850. Der politisch aktive Adel in Kroatien hatte so lange auf Latein beharrt, weil die Tradition dieser klassischen Sprache ein starkes Argument gegen die Einführung des Ungarischen bedeutete; bis Ende des 19. Jahrhunderts wurden intensive Anstrengungen zur Einführung des Ungarischen als Amtssprache in Zivilkroatien und Zivilslawonien unternommen. ${ }^{24}$

Vgl. Žepić: Zur Geschichte der deutschen Sprache.

Ebd., S. 219.

Kessler (Politik, Kultur und Gesellschaft, S. 134f.) hebt hervor, dass die Mehrsprachigkeit, trotz einer komplexen gesellschaftlichen und sprachlichen Situation, bis zum Auftakt der Illyrischen Bewegung bzw. bis zum Aufkommen der These von der Untrennbarkeit von Sprache und Nation kein Konfliktpotenzial hervorbrachte.

Brozović: Povijest, S. 69.

Vgl. Banac: Hrvatsko jezično pitanje; Tafra: Značenje narodnoga preporoda.

Banac: Hrvatsko jezično pitanje, S. 56.

Vgl. Sikirić Assouline: Latinitet u hrvatskom društvu.

Markus: Bogoslav Šulek, S. 1. 
Obwohl die Ideologie der Bewegung stark von negativen Haltungen gegenüber dem Gebrauch anderer Sprachen in den kroatischen Kronländern geprägt war, spielte die deutsche Sprache eine wichtige Rolle in den Sprachbiographien zahlreicher Illyristen. ${ }^{25}$ Die Ergebnisse der hier vorgestellten Untersuchung zeigen, dass Deutsch von den meisten Illyristen zeitlebens als Sprache ihrer literarischen und wissenschaftlichen Tätigkeit sowie des politischen Aktivismus verwendet wurde. Für viele war Deutsch die familiäre Vernakularsprache, während sie Kroatisch erst als Erwachsene erwarben (z.B. Dragojla Jarnević). Einige reflektieren über Sprachattrition (Abbau der Erstsprache bei einer Person) während des Militärdienstes oder bei längeren Aufenthalten im deutschen Sprachraum. ${ }^{26}$ Sämtliche Illyristen verfassten und veröffentlichten zeitlebens wissenschaftliche, journalistische oder literarische Texte auf Deutsch, so z.B. Ljudevit Vukotinović. Paradoxerweise verlangten sie von ihrer sprachlichen Umgebung genau das Gegenteil, ein Idealverhalten, dem sie selbst nicht nachkommen konnten: die ausnahmslose Verwendung der Nationalsprache.

Obwohl von intensiver institutioneller Germanisierung auf dem Gebiet der Militärgrenze gesprochen werden kann, ${ }^{27}$ ist der dominante Status des Deutschen in Zivilkroatien offenbar auf andere Ursachen zurückzuführen. In Zivilkroatien hatte Deutsch zwar nie amtssprachlichen Status gehabt, wurde jedoch in der ersten Hälfte des 19. Jahrhunderts als vorherrschende Verkehrssprache mit hohem Prestige benutzt, besonders in städtischen Gebieten. Die Dominanz des Deutschen war besonders beim Adel und beim mittleren und höheren Bürgerstand ausgeprägt. Die Ursachen liegen einerseits in den politischen und militärischen Beziehungen zum deutschen Sprachraum, andererseits in der jahrhundertelangen individuellen und kollektiven Ansiedlung deutschsprachiger Bevölkerung. ${ }^{28}$

Die zeitgenössischen Einflüsse auf die Generation der Illyristen waren nicht auf den Militärdienst und die Ausbildung an österreichischen Uni-

Vgl. Preradović: Crtice, S. 14

Militä 105 108) einzelne, dem ewigen Einerlei der Berufsgeschäfte abgerungene Laute meiner geringen Muse $\mathrm{zu}$ dir hinüber klingen zu lassen. Ich thue es gern, weil ich die Ueberzeugung habe verstanden zu werden, und thäte es noch lieber, wenn ich unserer Sprache so mächtig wäre, um meine Gefühle auch in das entsprechende vaterländische Gewand zu kleiden. « Kukuljević berichtet über ähnliche Probleme acht Jahre zuvor, in einem Brief aus Pressburg vom 25. Januar 1836 an Ljudevit Gaj (Deželić: Pisma - Građa, S. 117).

27 Häusler: Zur Geschichte des Deutschunterrichts.

28 Kessler: Politik, Kultur und Gesellschaft, S. 11; Stančić: Verschüttete Literatur, S. 50f. Žepić: Zur Geschichte der deutschen Sprache, S. 215. 
versitäten beschränkt. Lange vor der Gründung des kroatischsprachigen, illyrischen Theaters (1840) erfreute sich Zagreb einer lebendigen deutschsprachigen Kulturszene. Schriftsteller kroatischer Herkunft schrieben über lokale Themen auf Deutsch oder verfassten Bühnenstücke auf Deutsch für das Zagreber deutschsprachige Theater. ${ }^{29}$ Lokale deutschsprachige Zeitungen (z.B. »Agramer Zeitung «, 1830-1858) erschienen in Zagreb früher als kroatischsprachige, ${ }^{30}$ und selbst nach der Gründung erster kroatischsprachiger Zeitschriften (»Danica horvatska, slavonska i dalmatinska«, »Novine horvatske«, 1835-1849) $)^{31}$ erzielten die deutschsprachigen viel höhere Auflagen. ${ }^{32}$ Die meisten Buchhändler waren deutscher oder österreichischer Herkunft. Zeitgenössische Berichte zeugen von einer verbreiteten Vorliebe für deutschsprachige und einer Abneigung gegenüber kroatischsprachiger Literatur. ${ }^{33}$ Bis mindestens 1901 fand in Zagreb regelmäßig Gottesdienst in deutscher Sprache statt. ${ }^{34}$ Das Stadtbild war von deutschsprachiger Werbung, Aushängeschildern der Wirtshäuser und Handwerker geprägt. ${ }^{35}$ Zahlreiche Germanismen in den gegenwärtigen kajkavischen Dialekten im Nordwesten des Landes zeugen von der starken Präsenz des Deutschen in diesem Gebiet. ${ }^{36}$

Der Status des Deutschen ist offensichtlich nicht nur auf Transferprozesse und Wechselbeziehungen mit dem deutschen Sprachraum zurückzuführen. Das nordwestliche Kroatien der Wiedergeburtszeit kann in vielerlei Hinsicht (öffentliche Bereiche, Kultur, Konversation höherer Gesellschaftsschichten) als Teil des deutschen Sprachraumes bezeichnet werden. Der deutsche Indogermanist Hermann Hirt schreibt noch 1896: "In ganz Kroatien wird man kaum daran erinnert, dass man das deutsche Sprachgebiet verlassen hat, steht es doch seit Jahrhunderten unter dem Einfluß der deutschen Kultur; aber mit dem Betreten des bosnischen Bodens befindet man sich im Orient. « ${ }^{37}$

Vgl. Barac: Hrvatska književnost; Batušić: Uloga njemačkog kazališta; Stančić: Verschüttete Literatur.

30 Čizmić-Horvat: Deutschsprachige Presse.

31 Im Jahr 1836 ändern die Zeitungen ihre Namen in »Danica ilirska« bzw. »Novine ilirske« und veröffentlichen seitdem ausschließlich štokavische Texte.

32 Šidak et al.: Hrvatski narodni preporod, S. 137.

33 Barac: Hrvatska književnost, S. 144.

34 Vgl. Iz njemačkoga Zagreba, S. 18; Žepić: Zur Geschichte der deutschen Sprache, S. 218.

35 Vgl. Gavrin: Pjesništvo narodnoga preporoda, S. 51; Šidak et al.: Hrvatski narodni preporod, S. 119.

36 Vgl. u. a.: Medić: Kulturno-historijsko značenje; Turković: Deutsche Lehnwörter; Piškorec: Deutsches Lehngut; Piškorec: Germanizmi; Glovacki-Bernardi et al.: Agramer - rječnik njemačkih posudenica.

37 Zitiert nach Žepić: Zur Geschichte, S. 215. 


\section{Fragestellung, Korpus und Methodologie der Untersuchung}

Folgende Fragen sollen beantwortet werden: 1. Wie spiegelte sich die Einstellung zur deutschen Sprache im Diskurs der Illyristen wider? 2. Inwiefern entspricht die diskursive Schilderung des erwünschten patriotischen Sprachverhaltens dem realen Sprachverhalten der Mitglieder der illyrischen Bewegung?

Die vorliegende Untersuchung ging aus einem sprachbiographisch fundierten Forschungsrahmen hervor, in dem alle zugänglichen Texte und Selbstzeugnisse ${ }^{38}$ einzelner Illyristen in Bezug auf ihr Sprachverhalten im breitesten Sinne systematisch gesammelt und analysiert werden, um relevante Daten über die Dynamik gesellschaftlich-sprachlicher Prozesse zu erhalten. ${ }^{39}$ Von 2007 bis heute wurden Sprachbiographien von acht prominenten Mitgliedern der Bewegung anhand eines Untersuchungskorpus von über 600 Texten auf Kroatisch, Deutsch und Latein rekonstruiert. ${ }^{40}$ Das Korpus umfasst sowohl veröffentlichte journalistische, literarische und (populär)wissenschaftliche Texte, wie auch private Korrespondenz und zugängliche Tagebucheinträge.

Die sprachbiographische Methode in diesem historisch-soziolinguistischen Forschungsrahmen stützt sich auf verschiedene Ansätze, vor allem auf Domänenforschung, ${ }^{41}$ Sprachkontaktforschung, Untersuchung narrativer Identitä $t^{42}$ und kritische Diskursanalyse, in erster Linie auf den soziokognitiven Ansatz von van Dijk. ${ }^{43}$ Dabei werden die Texte auf folgenden Ebenen analysiert, jeweils mit besonderer Berücksichtigung zeitlicher Veränderungen im Sprachverhalten:

1. Kodewahl und Kodewechsel (Kajkavisch, Štokavisch, Deutsch, Latein, andere Sprachen);

Zu den Termini Selbstzeugnis bzw. Ego-Dokument s. Rutz: Ego-Dokument.

Die Synthese bisheriger Fallstudien wird vorgestellt in: Novak: Višejezičnost. Folgendes sei hinzugefügt: Ältere Untersuchungen befassten sich entweder mit dem >literarischen Bilinguismus kroatischer Schriftsteller (vgl. Badalić: Pjesništvo narodnoga preporoda; Gavrin: O bilingvizmu), der deutschsprachigen Literatur in Zivilkroatien (vgl. Stančić: Verschüttete Literatur) oder der Rolle des Deutschen in den Sprachbiographien der Mitglieder der illyrischen Bewegung (vgl. Novak: Višejezičnost). Der vorliegende Beitrag ist die erste detaillierte Diskursanalyse der Einstellung gegenüber der deutschen Sprache in der Zeit der Kroatischen Nationalen Wiedergeburt.

40 Ljudevit Gaj (1809-1872), Dragojla Jarnević (1813-1875), Ivan Kukuljević Sakcinski (18161889), Petar Preradović (1818-1872), Dragutin Rakovac (1813-1854), Ivan Trnski (1819-1910) Adolfo Veber Tkalčević (1825-1889), Ljudevit Vukotinović (1813-1893).

41 Vgl. Fishman: Who Speaks What Language to Whom and When?

Vgl. Deppermann/Lucius-Hoene: Rekonstruktion narrativer Identität.

Vgl. Van Dijk: Discourse and Context. 
2. Anwendung neuer grammatischer und orthographischer Lösungen in Texten auf Kroatisch;

3. Reflexionen und narrative Muster des Autors bzw. der Autorin in Äußerungen zum eigenen Sprachverhalten und zum erwünschten, tatsächlichen oder missbilligten Sprachverhalten in der gesellschaftlichen Umgebung;

4. Reflexionen über die Zugehörigkeit zu einer bestimmten kollektiven Identität (kroatisch, illyrisch, südslawisch, panslawisch, transleithanisch, monarchisch, ggf. auch Zugehörigkeit zu einer bestimmten sozialen Schicht).

Die gewonnenen Einsichten werden durch Texte anderer Personen trianguliert, in denen das Sprachverhalten des Autors bzw. der Autorin kommentiert wird. Damit werden relevante Daten nicht nur zum konkreten Sprachverhalten der Person, sondern auch zu ideologischen Merkmalen und dadurch zur Motivation für ein bestimmtes Sprachverhalten gewonnen. Wir sind der Auffassung, dass die Gruppenideologie sehr wohl das Sprachverhalten des Individuums beeinflussen kann. ${ }^{44}$

In dem skizzierten Forschungsrahmen lag bislang keine Synthese vor, die sich ausschließlich mit der Einstellung zur deutschen Sprache befasst. Für die vorliegende Fragestellung bieten die verfügbaren Texte jedoch genügend fundierte Einsichten in den Status und die vorherrschenden Haltungen gegenüber der deutschen Sprache bei den Mitgliedern der Illyrischen Bewegung. Dabei gehen wir von der Annahme aus, dass anhand von Reflexionen einer Person Diskursmerkmale und die Logik narrativer Konstruktionen ermittelt werden können, mit denen die Person sich selbst, andere Menschen, soziale Praktiken und Sprachverhalten positioniert. Aufgrund individueller Stellungnahmen werden Haltungen gegenüber dem realen und dem erwünschten Status der deutschen Sprache erkennbar.

Analysiert wurden sämtliche Texte aus dem öffentlichen und dem privaten Bereich, die sich zentral oder auch nur marginal mit dem Thema der zeitgenössischen gesellschaftlich-sprachlichen Situation befassen. Berücksichtigt werden Texte der oben genannten acht AutorInnen (vgl. Anm.

44 Für die Untersuchung der Illyristen, die als äußerst sprachbewusste Personen intensiv und kritisch über eigenes Sprachverhalten und die zeitgenössische soziolinguistische Situation berichten, hat sich der vorliegende historisch-sprachbiographische Ansatz als fruchtbar erwiesen. Weniger produktiv ist der Ansatz vermutlich, wenn es um analphabetische Personen und soziofunktionale Gruppen geht, oder um Gruppen, für die sprachliche Phänomene keine wichtige Rolle spielen. Eine weitere Beschränkung der Methode liegt im Bereich der Korpora: für etliche Texte aus dieser Zeit ist die Verfasserschaft umstritten, außerdem sind höchstwahrscheinlich viele Texte einzelner Personen im Laufe der Zeit verloren gegangen. 
40) im Zeitrahmen 1830 bis 1890 . Zusätzlich wurde die Kodewahl der AutorInnen in unterschiedlichen Textsorten und Bereichen im biographischen Verlauf beobachtet, um festzustellen, in welchem Verhältnis das erwünschte und das reale Sprachverhalten der Illyristen stehen. Wegen Platzmangel ist es nicht möglich, für alle Thesen Beispiele vorzulegen. Deswegen wird auf einzelne Quellen verwiesen, in denen die erwähnten diskursiven Merkmale erkennbar sind. Vorgestellt werden ausschließlich Merkmale, die vielfach bzw. in Texten verschiedener Mitglieder der Bewegung nachzuweisen sind.

\section{Analyse}

\subsection{Negative Einstellungen}

Drei ausgeprägte narrative Muster bezüglich der deutschen Sprache sind in den Texten der Illyristen zu verzeichnen:

1. Der Fortschritt und ein glückliches Dasein eines jeden Volkes kann nur durch Bildung, und die Bildung nur durch eine ausgebaute Nationalsprache gesichert werden. ${ }^{45}$

2. Deutsch verdrängt - als dominante institutionelle Verkehrssprache - die kroatische Sprache, was fatale Konsequenzen für die kroatische bzw. illyrische Nationalität haben kann.

3. Schuld daran sind vor allem das kroatische Bürgertum und die Adeligen, die Deutsch verwenden - und zwar nicht nur, wenn es situativ bedingt ist - und somit den Status dieser Sprache untermauern. ${ }^{46}$

Die Verdrängung des Kroatischen durch fremde Sprachen, insbesondere durch das Deutsche, wird in den Texten der Illyristen oft hervorgehoben. Dabei werden vor allem offizielle bzw. amtliche Bereiche erwähnt, in denen Latein und Deutsch Verkehrssprachen sind. Diese Sprachen werden außerdem als Medien genannt, die nicht allen Bürgern gleich zugänglich sind und daher als Instrumente der Machtinhaber fungieren. Der Anführer der Bewegung Ljudevit Gaj äußert sich darüber in seinem autobiographischen Text Vjekopisni moj nacrtak (1875):

Vgl. u.a. Rakovac: Mali katekizam, S. 127f.; Vukotinović: Zimske misli; Gaj: Vjekopisni moj nacrtak.

46 Vgl. Gaj: Nima domorodztva; Vukotinović: Zimske misli, S. 160; Jarnević: Dnevnik, S. 142 (Tagebucheintrag vom 23. Januar 1840). 
>[...] svemu je ovomu ubožtvu<, reći će, >uzrok, što je ovaj narod po gospodi sasvim zanemaren i napušten, počem i duhovna i svjetovna gospoda u latinskom i njemačkom jeziku kriju svu znanost i naučnost svoju, siromašnoj braći svojoj iste krvi ne dajući ni najmanje svjetlosti naučne na materinskom jeziku. [...] ${ }^{47}$

Dieser Logik folgend werden deutsche Transferenzen (Übernahme fremdsprachiger Elemente) in kroatischen Idiomen nicht nur als > Verschmutzung «, sondern auch als Gefahr dargestellt. Der Verlust der nationalen Sprache könne nämlich fatale Konsequenzen haben: das Volk verliere ohne eigene Sprache seine Identität, Sprachverlust führe zur >Entvölkung` (>odnarođenjeく bzw. >odnarođivanjeく: ein im Diskurs der Illyristen stark verbreiteter Neologismus). ${ }^{48}$ Die Verbundenheit von Sprache und sozialer Gruppe ist im Diskurs der Illyristen so weitreichend, dass die These aufkommt, eine Fremdsprache könne die Mentalität und das Verhalten des Einzelnen und der Gruppe direkt verändern. ${ }^{49}$

Bemerkenswert dabei ist, dass die negative Einstellung gegenüber der deutschen Sprache nur sehr selten assoziativ auf Österreicher oder Deutsche übertragen wird. Das wahre Schlachtfeld zwischen den Idiomen sind in diesem Sinne vor allem Menschen sillyrischer bzw. südslawischer Herkunft. Denn die Schuld am privilegierten Status des Deutschen geben die Illyristen dem kroatischen Adel und dem Bürgertum bzw. gebildeten Mitgliedern der mittleren und höheren Stände, die in privaten und öffentlichen Angelegenheiten ausschließlich Deutsch verwenden. Mit besonderer Verachtung werden jene kritisiert, die auf korrektes Deutsch achten, während sie ohne alle Scham schlechtes Kroatisch sprechen, sowie diejenigen, die literarische Texte (ausschließlich) auf Deutsch verfassen. Die Vernachlässigung der eigenen Sprache wird außerdem als unverantwortlich, kurzsichtig und für das Volk gefährlich dargestellt. ${ }^{50}$

Als wünschenswertes patriotisches Sprachverhalten gilt im Diskurs der Illyristen der aktive Ausbau und Gebrauch der Nationalsprache in allen möglichen Gelegenheiten, sowie die intensive Produktion und Publikation literarischer, linguistischer, journalistischer, historiographischer und politischer Texte in der Nationalsprache. ${ }^{51}$ Damit beweise man ihre Fähigkeit

Zit. nach Brešić: Autobiografije, S. 131-141.

Siehe hierzu: Kukuljević Sakcinski: Što će biti iz nas?, S. 130f.; Kukuljević Sakcinski: Rede im Sabor (s. Anm. 16); Vukotinović: Zimske misli.

Gaj: Vjekopisni moj nacrtak, S. 133; Kukuljević: Rede im Sabor, S. 158.

Siehe die in Anm. 45 genannten Quellen, außerdem: Vukotinović: Zimske misli; Kukuljević: Rede im Sabor.

1 Vgl. Vukotinović: Zimske misli; Jarnević: Dnevnik, S. 142 (Tagebucheintrag vom 23.1.1840), S. 345 (20.8.1848), S. 544 (21.7.1855), S. 750 (14.7.1874); Gaj: Kratka osnova, S. 39; Gaj: Nima domorodztva. 
zur Übernahme aller wichtigen Funktionen und bilde einen großen Korpus zeitgenössischer Texte, die als Vorbild für weiteres Schaffen in der Nationalsprache dienten. Zudem solle jeder Patriot auch auf seine Umgebung einwirken. In programmatischen Texten werden Mitglieder, Sympathisanten der Bewegung und alle Bürger der kroatischen Kronländer aufgefordert, Kroatisch statt Deutsch oder Ungarisch zu gebrauchen, ${ }^{52}$ sogar versuchen, Kroatisch stets als Konversationssprache aufzuzwingen. Dennoch wird häufig zugegeben, dass Deutsch-, Ungarisch- und Lateinkenntnisse vorteilhaft in der Karriere seien, im Gegensatz zur soliden Kompetenz im Kroatischen. Man solle Bekannte auffordern, sich dem Erlernen der Nationalsprache zu widmen, ihnen zu gutem Gebrauch raten, die Gründe für die Förderung der Nationalsprache erläutern und allen jenen ins Gewissen reden, die sich vornehmlich auf Deutsch unterhalten. Ein solches Sprachverhalten wird als unnötig, modisch, manchmal auch angeberisch und hochstaplerisch kritisiert und im Diskurs der Illyristen häufig mit den pejorativen Ausdrücken >švabčarenje< bzw. ıněmčarenje belegt. $^{53}$

Insgesamt kommen in der kritischen Schilderung der gesellschaftlichsprachlichen Situation und der Lage des Deutschen in Zivilkroatien vier Oppositionen zum Ausdruck:

1. städtisch - ländlich;

2. nordwestlich - südöstlich;

3. Gegenwart - Vergangenheit;

4. höhere - niedrigere Gesellschaftsschichten. ${ }^{54}$

Die jeweils erstgenannten Elemente werden mit der Vormachtstellung der deutschen Sprache in Verbindung gebracht, die jeweils zweitgenannten mit einer stärkeren Position der kroatischen Dialekte und einem ausgeprägteren nationalen Selbstbewusstsein. ${ }^{55}$ Deutsch war demnach in städtischen

52 Vgl. u.a. Veber Tkalčević: Brief an Dragojla Jarnević vom 17.11.1854; Jarnević: Dnevnik, S. 184, 601, 620; Preradović: Brief an Ivan Kukuljević Sakcinski (s. Anm. 26); ders.: Brief an Ivan Trnski vom 24.11.1861; ders.: Brief an Ivan Trnski vom 2.1.1870. Außerdem sind mehrere Briefe von Petar Preradović an seine Verlobte Ema Regner zugänglich, in denen er sich über ihre Fortschritte im Kroatischlernen erkundigt. Siehe hierzu: Škreb: Preradovićeva pisma (bes. aufschlussreich: die Briefe vom 17.7.1859, S. 23, und vom 14.2.1861, S. 55).

53 Bestätigt als Deverbativa und als Verben. Vgl. u.a. Jarnević: Dnevnik, S. 450 (Tagebucheintrag vom 6.4.1852), S. 544 (21.7.1855); Trnski: Brief an Dragojla Jarnević vom 26.10.1939; Vukotinović: Zimske misli.

54 Alle vier Oppositionen können als stabile Merkmale des Diskurses der Illyrischen Bewegung betrachtet werden. Deutlich erkennbar sind alle vier in Kukuljević Sakcinski: Put u Senj, S. 188. Auch in: ders.: Die Nationalität in Kroatien. S. hierzu: Novak: Višejezičnost, S. $400 \mathrm{ff}$.

55 Es ist jedoch zu bezweifeln, dass dies ein Resultat der sog. nationalen Wiedergeburt war. Durch Wiedergeburtsaktivitäten wurden, wie bereits erläutert, keine breite Volksmassen aktiviert. 
Umgebungen, im Nordwesten Kroatiens bzw. in Zivilkroatien, in der Gegenwart und in höheren Gesellschaftsschichten stark vertreten.

Da sämtliche Mitglieder der Bewegung in Familien aufgewachsen waren, in denen ausschließlich Deutsch gesprochen wurde, und Kroatisch erst als Erwachsene gelernt hatten, ist auch eine Redefinierung des Terminus >Muttersprache im Diskurs zu verzeichnen. Die Muttersprache stellt für die Illyristen nicht jenes Idiom dar, das sie in der frühen Kindheit ohne Unterricht erworben hatten (dies war in vielen Fällen Deutsch), sondern die Sprache ihrer deklarierten ethnischen/nationalen Zugehörigkeit (Kroatisch bzw. >Illyrisch $<)^{56}$

\subsection{Positive Einstellungen}

Die Präsenz einer vorwiegend negativen Einstellung gegenüber der deutschen Sprache im Diskurs der Illyristen war angesichts der bekannten Merkmale der illyristischen Ideologie vorhersehbar. Weniger erwartungsgemäß hingegen war die Einsicht, dass Deutsch teilweise auch mit äußerst positiven Konzepten assoziiert wurde. Zum einen war Deutsch als eine in hohem Maße ausgebaute Sprache ein vorbildliches Modell für die zu entstehende >illyrische Literatursprache. Zum anderen spielte sie in den ersten Phasen der Bewegung auch eine wichtige Rolle als interlinguistische >Hilfssprache`, d.h. als ein Medium für den Erwerb und Implementierung der neuen, sillyrischen< Literatursprache. In diesem Sinne kann von einer Überbrückungsfunktion des Deutschen gesprochen werden. Außerdem blieb sie in den Sprachbiographien vieler Illyristen zeitlebens präsent.

Deutsch wird in den Texten der Illyristen als vorbildlich präzise kodifizierte, weitgehend standardisierte und fortgeschrittene Sprache mit großer literarischer und politischer Tradition geschildert. Zudem wird die enthusiastische Spracharbeit der Deutschen (sowie die Arbeit der Ungarn an ihrer Nationalsprache) als erstrebenswertes Ideal und vorbildliches patriotisches Verhalten bezeichnet. ${ }^{57}$

56 Siehe hierzu bspw. Jarnević: Dnevnik, S. 120 (Tagebucheintrag vom 13.7.1839): »Izgubili se naši gosti, i opet je mir u kući. Dobitak što mi osta po njima jest: da sam slušala i ponešto učila hrvatski moj materinski jezik. " Hier ist ersichtlich, dass die Autorin Kroatisch einerseits als Muttersprache bezeichnet, aber andererseits auch als Idiom, dessen sie nicht mächtig ist. Dies ist keineswegs ein isoliertes Phänomen. In diesem Zusammenhang kann ein Vergleich zu der heutigen russlanddeutschen Minderheit gezogen werden, deren Mitglieder als Muttersprache Deutsch angeben, obwohl die meisten nur über passive Deutschkenntnisse verfügen. Hierzu s. Riehl: Sprachkontaktforschung, S. 153.

57 Vgl. u.a. Vukotinović: Zimske misli, S. 160; ders.: Uspomena na godine 1833-35, S. 94; Kukuljević Sakcinski: Rede im Abgeordnetenhaus. 
Außerdem wurde der Gebrauch des Deutschen nicht in allen Kontexten kritisiert. Betont wird die im Allgemeinen positive Auswirkung von Fremdsprachenkenntnissen auf das Leben jeder gebildeten Person, und gerade Gebildete sind der dringendste Bedarf des Volkes. ${ }^{58}$ Deutsch- und Ungarischkenntnisse ermöglichten außerdem die erforderliche historiographische Forschungsarbeit. ${ }^{59}$ Das Erforschen der glorreichen Geschichte der >illyrischen` (i.S.v. >südslawischen`) Völker nahm neben der Spracharbeit einen besonderen Stellenwert in der illyristischen Ideologie ein. Von der Historiographie erhoffte man sich die Bestätigung der wichtigen Rolle der illyrischen Völker in der Abwehr und im Fortschritt des Abendlandes, somit auch eine Rechtfertigung für die Existenz dieser Nationen. ${ }^{60}$

Da ein Großteil der jüngeren kroatischen Intelligenz damals der Volkssprache nicht mächtig war, wurde Deutsch auch als berechtigtes Instrument zur Verbreitung illyristischer Ideen anerkannt. Sämtliche programmatische bzw. apologetische Texte der Illyristen wurden anstatt auf Kroatisch entweder ausschließlich auf Deutsch oder zweisprachig veröffentlicht. ${ }^{61} \mathrm{Im}$ Diskurs wurde dies mit der Erreichbarkeit auch anders gesinnter Teile der Leserschaft durch deutschsprachige politische Texte sowie mit der höheren Auflage deutschsprachiger Zeitungen begründet.

Obwohl in zahlreichen Texten der Illyristen alle patriotisch Gesinnten aufgefordert wurden, ihre Texte auf Kroatisch zu verfassen und zu veröffentlichen, hielten sich nicht einmal die bekanntesten Illyristen an diese Anforderung. Die bisherigen Ergebnisse der sprachbiographischen Rekonstruktion haben erwiesen, dass beispielsweise ein beträchtlicher Teil der Korrespondenz der Illyristen mit Mitgliedern anderer slawischer Nationalbewegungen weiterhin auf Deutsch geführt wurde. ${ }^{62}$ Mitglieder verschiedener slawischer Nationalbewegungen schrieben einander allerdings oft in ihren eigenen Muttersprachen (Slowakisch, Tschechisch, Polnisch usw.).

Auch (populär)wissenschaftliche Texte veröffentlichten einige Illyristen zeitlebens auf Deutsch, mit der Begründung, es sei die internationale

58 Vgl. u.a. Vukotinović: Offenes Sendschreiben.

59 S. Gaj: Vjekopisni moj nacrtak, S. 133f. u. 135; ders.: Ein Fragewort über Croatien.

60 Vgl. u.a. Vukotinović: Ilirisam i Kroatisam; Kukuljević: Die Nationalität in Kroatien; ders.: Die legitimen und historischen Rechte. Eine detailliertere Analyse von Kukuljevićs Ansichten in diesem Zusammenhang: Novak: Višejezičnost, S. 370 u. $406 \mathrm{f}$.

61 Vgl. u.a. Rakovac: Mali katekizam/Kleiner Katechismus; Vukotinović: Offenes Sendschreiben; ders.: Skizzen über das Slawenthum, S. 170; Gaj: Ein Fragewort; Kukuljević: Die Nationalität; ders.: Kakva trěba da bude u obće politika naša. Dieser in »Novine dalmatinsko-hervatsko-slavonske« veröffentlichte Artikel erschien eine Woche später, am 27. April 1848, auch auf Deutsch in der »Agramer Zeitung« Nr. 44 unter dem Titel Wie soll unsere gemeinsame Politik beschaffen sein?

62 Vgl. u.a. Rakovac: Brief an Pavel Josef Šafařík.; Gaj: Konzept eines Briefes an Pavel Josef Šafařík. Außerdem weitere Briefe auf Deutsch zwischen 1831 und 1837 in: Deželić: Pisma. 
Sprache der Wissenschaft. Für historiographische Texte galt zudem, dass sie auf Deutsch national unbewusste Personen erreichen, und diese benötigten es am meisten, mit den Verdiensten der illyrischen Völker für das Abendland bekanntgemacht zu werden. Die Sprachbiographie von Ljudevit Farkaš Vukotinović ist ein eklatantes Beispiel für diesen doppelten Maßstab. Vukotinović war einer der schärfsten Kritiker des Deutschgebrauchs in der kroatischen Gesellschaft; er wurde in der Zeit des Neoabsolutismus sogar entlassen, weil er sich weigerte, im Dienst Deutsch zu sprechen. ${ }^{63}$ Vukotinović schrieb aber zugleich alle wissenschaftlichen Arbeiten in den Bereichen Mineralogie und Geologie sowie eine Reihe von polemischen Texten auf Deutsch, und zwar in deutschen Zeitungen, in denen er die illyristische Ideologie und Spracharbeit verteidigt. ${ }^{64}$

Deutsch blieb teilweise Konversationssprache, sogar im engsten Kreis der Anführer der Bewegung. In welchen Situationen, in welchem Ausmaß und in welchen Phasen, dies ist nicht leicht zu rekonstruieren, es gibt jedoch zahlreiche Berichte, die darauf hindeuten. Davon zeugen unter anderem die Tagebucheinträge von Dragojla Jarnević über den Kreis der Illyristen um den Abt Ivan Krizmanić in dem kroatischen Wallfahrtsort Marija Bistrica sowie über ihr Verhältnis mit dem Illyristen Ivan Trnski. ${ }^{65}$

Deutsch blieb für die Illyristen in geringerem Ausmaß auch Sprache des literarischen Schaffens. ${ }^{66}$ Die SchriftstellerInnen unter den Illyristen reflektieren des Öfteren darüber, dass sie sich nicht kompetent genug im Kroatischen fühlen ${ }^{67}$ und dass die deutsche Sprache vielfältigere Ausdrucksmöglichkeiten biete als die kroatische ${ }^{68}$ Einige Mitglieder der Bewegung

63 Vgl. Deželić: Iz njemačkoga Zagreba, S. 59-61; Barac: Hrvatska književnost, S. 203.

64 In seinem Text Tri stvari knjiženstva erklärt Vukotinović den Unterschied zwischen der Kodewahl im literarischen und im wissenschatlichen Handeln: „Što se pako ukusa tiče, to se mi svi spisatelji tarsiti imamo, da se onoga najvećma daržimo, što je narodno. Osim znanstvenih dêlah, koja su ustrojena više manje svigdê polag jednog značaja, trêba da poetička strana knjiženstva slavenski značaj na sebi nosi.« (Tri stvari knjiženstva, S. 152). Zur Bibliographie von Vukotinovićs wissenschaftlichen Werken auf Deutsch siehe: Magaš/Kochansky-Devide: Geološka bibliografija.

65 Siehe hierzu zahlreiche Schilderungen von Gesprächssituationen in Jarnević: Dnevnik, S. $576 f$.

66 Dragojla Jarnević schrieb am Silvesterabend 1841 folgendes: »Und durch dieses ganzen Jahres Lauf endfloss mir kein deutsches Wort - aber heute als am Ende eines für mich sehr denkwürdigen Laufes kann ich mich doch nicht enthalten in der mir ewig theuern Sprache einige Zeilen in mein Tagebuch niderzuschreiben." (Dnevnik, S. 184).

67 Vgl. Rakovac: Brief an Ljudevit Gaj vom 1.4.1831; Preradović: Brief an Ivan Kukuljević (s. Anm. 26); ders.: Brief an Ivan Kukuljević Sakcinski vom 29.2.1844; Jarnević: Dnevnik, S. 97 (Tagebucheintrag vom 26.10.1837), S. 105 (20.5.1838), S. 177 (1.1.1841), S. 179 (27.2.1841).

68 Dragojla Jarnević berichtet öfters über solche Probleme. »Odviše malo vremena za čitati mi ostaje, a neuviežbana u materinskom jeziku šta u njemu izverstno a pisati možem?! nikako se moj duh tako visoko zavesti neće, kada u ilirskom jeziku iz njega govorim nikako mi reći i izrazi 
übten sich in der kroatischen Sprache, indem sie literarische Texte aus dem Deutschen übersetzten. ${ }^{69}$ Es gibt weitere Argumente für die These, dass Deutsch den Illyristen als Hilfssprache für den Erwerb und Implementierung der neuen Literatursprache diente. ${ }^{70}$

Wie bereits erwähnt, funktionierten die Illyristen als soziales Netzwerk in dem jene, die kompetenter in Kroatisch waren, diejenigen unterstützten, die die Sprache erst erlernen mussten. Dabei ging es nicht nur um guten Stil, sondern oft ganz einfach um den richtigen kroatischen Ausdruck. Denn weder die kroatischen lokalen Idiome, noch die historisch-literarischen Vorbilder der Illyristen boten eine ausreichende lexikalische Vielfalt, um den Bedarf einer modernen polyfunktionalen Nationalsprache decken zu können. Aus diesem Grund befassten sich die Illyristen besonders intensiv mit Wortbildung und Lexikographie. Um neue Ausdrücke leichter präsentieren und implementieren zu können, bedienten sich die Illyristen sowohl in privater Korrespondenz als auch in journalistischen Texten deutscher Übersetzungsäquivalente. Es folgt ein Beispiel aus der Privatkorrespondenz von Ivan Trnski und Dragojla Jarnević. Deutsche, in geringerem Maße auch lateinische Übersetzungsäquivalente dienen im Text zur Erklärung unbekannter und neuer kroatischer Ausdrücke:

Najprě, tako rekući, tužiš sama sebe, plemenita dušo, da zaludu hvataš i tražiš rěči, kojimi bi ono izrazila (ausdrücken würdest), što tako silno dubinu tvoga serca puni (füllt), i u vis těra krila od Tvoje plemenite duše! A što je tome uzrok? Jerbo je nesrětno němčarenje učinilo, da smo skoro svi i němački mislili - da i sad mnogi němački misle, a tudjinski misleći, kako ćemo naški misli ote pobilěžiti (aufzeichnen)? [...] I ja sam prije latinštini i němčarenju služio, njima sam robova (ihr Sklave war ich), nu verige padoše na žertveniku od domoljublja i - nije mi težko bit Ilirom. [...]. Kad dakle, dušo, takve sposobnosti (Eigenschaften) posěduješ (besitzest), pitaj se sama, šta si dužna učinit’ Ili francezki jezik veću vrědnost za Te imade? ${ }^{71}$

Dragojla Jarnević bestätigt die Funktion der Übersetzungsäquivalente in ihrem Tagebuch: »Ali on piše hrvatski i gde što nerazumiem smisao, on

mi neslužiju, kako mi jih nemački ponudja (...) « (Dnevnik, S. 184). »Za desetu svaku njemačku rieč nalazi se tek jedna hrvatska.« (ebd., S. 108).

69 Vgl. Gavrin: Pjesništvo narodnoga preporoda; Badalić: O bilingvizmu.

70 Über die vermittelnde Rolle des Deutschen schreibt auch Daniel Baric (Langue allemande, identité croate), mit der Schlussfolgerung, die moderne kroatische mitteleuropäische Identität habe sich in enger Wechselbeziehung mit der deutschsprachigen Welt herausgebildet. Da eine Übersetzung dieser Monographie zum Zeitpunkt der Einreichung dieser Arbeit noch aussteht und die Autoren des Französischen nicht mächtig sind, stammen ihre Informationen über Barics Thesen vorläufig aus der Buchbesprechung von Marijan Bobinac (Bobinac: Deutsche Sprache, kroatische Identität, S. $111 \mathrm{ff}$.).

71 Trnski: Brief an Dragojla Jarnević vom 26.10.1839. 
pomaže niemačkom rieči tumačiti i tako mi je njegovo pismo i zadaća hrvatskoga jezika. «"2

\section{Schlussbemerkungen}

Obwohl die Illyristen äußerst kritisch gegenüber dem Gebrauch von Fremdsprachen waren und besonders die deutsche Sprache als Bedrohung für die nationale Identität darstellten, zeigt die Analyse, dass Deutsch im Diskurs der illyrischen Bewegung nicht die Funktion eines Hassobjektes einnahm. Vertreter der Bewegung äußerten sich in erster Linie kritisch gegenüber Landsleuten, die kein Nationalbewusstsein besaßen, sowie gegenüber dem unverantwortlichen Vermeiden der Nationalsprache und dem als modisch und hochstaplerisch bezeichneten, situativ nicht notwendigen Gebrauch des Deutschen in höheren Gesellschaftsschichten.

Die Illyristen schilderten häufig wünschenswerte patriotische Vorgehensweisen und zeigten mit eigenem beispielhaften Handeln, dass die Nationalsprache bereit ist, die Stelle der deutschen und der lateinischen Sprache in öffentlichen und privaten Bereichen einzunehmen. Durch ihre Aktivitäten wurde die Nationalsprache zur Ikone, zur Ressource, zum immateriellen Gut der Nation. Sprache war für die Illyristen nicht nur Gegenstand der Identifikation; durch die Sprache sah man sich sogar im Stande, eine verlorengegangene Identität wiederherzustellen. Demnach kann die Spracharbeit der Illyristen auch als Totemisierung und Reifizierung der Sprache bezeichnet werden. ${ }^{73}$

Deutsch blieb dennoch in beträchtlichem Maße auch im Sprachverhalten der Mitglieder der Illyrischen Bewegung präsent, und zwar als Konversationssprache, Sprache der privaten Korrespondenz, (populär) wissenschaftlicher, politischer, journalistisch-polemischer Texte, in geringerem Maße auch Sprache des literarischen Schaffens. Dies zeugt unserer Ansicht nach nicht nur von der damaligen Dominanz der deutschen Sprache im nordwestlichen Kroatien, sondern auch von der Tatsache, dass alle soziale Praktiken in diesem Gebiet von langanhaltenden Verhältnissen im

72 Jarnević: Dnevnik, S. 135. Zu weiteren Beispielen von Übersetzungsäquivalenten s. Novak: Višejezičnost, S. 276. Ihre Anwendung ist nicht nur auf private Korrespondenz begrenzt. In den ersten Jgg. der illyrischen Zeitschriften Danica und Novine sind sie zahlreich vertreten (Digitalisat: <http://dnc.nsk.hr/Newspapers/LibraryTitle.aspx?id=1a7779a8-ef40-4ec3-a675$2372 \mathrm{c} 673 \mathrm{a} 3 \mathrm{c} 3>$ ).

73 Vgl. Tabouret-Keller: Language and Identity. 
geopolitischen, linguistischen und kulturellen Raum zwischen der Donau und dem Adriabecken nachhaltig geprägt waren.

Die Aktivitäten der Illyrischen Bewegung waren zwar auf die Formierung einer neuen Nation ausgerichtet, einerseits durch die Wiederherstellung von teilweise verlorengegangenen Bezügen zu der eigenen Geschichte und zum eigenen kulturellen Erbe, andererseits durch sex negativo Definitionen in Bezug auf andere kollektive bzw. nationale Identitäten. Mit Vorliebe stützten sich die Illyristen auf Verfahren und Ergebnisse der sog. Wiedergeburtsbewegungen anderer slawischer Nationen. Allerdings knüpften ihre Vorgehensweisen auch an literarische, wissenschaftliche, kulturelle, sprachwissenschaftliche und politische Vorbilder aus dem deutschen Sprachraum an. Die hier vorgestellte Analyse führt also zu der Annahme, dass die Illyristen besonders bei der Kodifizierung, Förderung und diskursiven Verteidigung der neuen Nationalsprache auf Deutsch als Medium und als Leitbild angewiesen waren.

\section{Literaturverzeichnis}

\section{Quellen}

Gaj, Ljudevit: Ein Fragewort über Croatien im Anfange des neunten Jahrhunderts. In: Ljudevit Gajs Nachlass in der National- und Universitätsbibliothek Zagreb, Sign. R 4701 A V. 19.

Gaj, Ljudevit: Gedanken zum Ausgleich Croatiens und Slawoniens mit der Regierung [1864]. <http://books.google.com/books?id=Px4RAQAAIAAJ\&printsec $=$ frontcover\&dq=Lj udevit+Gaj+Gedanken+zum+Ausgleich\&lr=\&as_brr=3\&ei=kd3uS4HxCqKwywTK jODaCg\&cd=1\#v=onepage\&q\&f=false $>$ (Zugriff: 20.5.2015).

Gaj, Ljudevit: Konzept eines Briefes an Pavel Josef Šafařík aus dem Jahre 1830. In: Pisma pisana Dru. Ludevitu Gaju i ńeki ńegovi sastavci (1828-1850). Hg. Velimir Deželić. Građa za povijest kniževnosti hrvatske 6. Zagreb: JAZU 1909, S. 337-339.

Gaj, Ljudevit: Kratka osnova horvatsko-slavenskoga pravopisaňa, poleg mudrolubneh narodneh i prigospodarneh temelov i zrokov [1830]. In: Miroslav Šicel: Riznica ilirska 1835-1985. Zagreb, Ljubljana: Nakladni zavod Matice hrvatske, Cankarjeva založba 1985, S. 39-44.

Gaj, Ljudevit: Nima domorodztva prez lyubavi materinzkog jezika. »Danica horvatska slavonska i dalmatinska« 17-21 (I) 1835.

Gaj, Ljudevit: Vjekopisni moj nacrtak [1875]. In: Autobiografije hrvatskh pisaca. Hg. Vinko Brešić. Zagreb: AGM 1997, S. 131-141.

Jarnević, Dragojla: Dnevnik [Tagebucheinträge 1833-1874]. Karlovac: Matica hrvatska 2000.

Kukuljević Sakcinski, Ivan: Brief aus Pressburg vom 25. Januar 1836 an Ljudevit Gaj. In: Pisma pisana Dru. Ludevitu Gaju i ńeki ńegovi sastavci (1828-1850). Građa za povijest kniževnosti hrvatske 6. Hg. Velimir Deželić. Zagreb: JAZU 1909, S. 117.

Kukuljević Sakcinski, Ivan: Die legitimen und historischen Rechte Croatiens und der Ausgleich mit Ungarn. Wien: F.B. Geitler 1871. 
Kukuljević Sakcinski, Ivan: Die Nationalität in Kroatien und Slavonien von J. Kukuljević v. Sacci (Aus dem Beiblatte »Luna« der Agramer polit. Zeitung besonders abgedruckt). Zagreb: Ljudevit Gajs Druckerei 1842.

Kukuljević Sakcinski, Ivan: Kakva trěba da bude u obće politika naša. »Novine dalmatinskohervatsko-slavonske« 37 (20.4.1848).

Kukuljević Sakcinski, Ivan: Put u Senj [1843]. In: Miroslav Šicel: Riznica ilirska 1835-1985. Zagreb, Ljubljana: Nakladni zavod Matice hrvatske, Cankarjeva založba 1985.

Kukuljević Sakcinski, Ivan: Rede im Abgeordnetenhaus der Varaždiner Gespannschaft vom 28. September 1843. In: Stjepan Mirković: Ivan Kukuljević Sakcinski. Zagreb: Dragutin Albrecht 1861, S. 18-23.

Kukuljević Sakcinski, Ivan: Rede im Sabor vom 2. Mai 1843. In: Programski spisi hrvatskog narodnog preporoda. Hg. Miroslav Šicel. Zagreb: Matica hrvatska 1997, S. 151-167.

Kukuljević Sakcinski, Ivan: Što će biti iz nas? [1843, wegen Zensur unveröffentlicht]. In: Tadija Smičiklas: Život i djela Ivana Kukuljevića Sakcinskoga. »Rad JAZU« 1892, S. 110-204.

Kukuljević Sakcinski, Ivan: Wie soll unsere gemeinsame Politik beschaffen sein? »Agramer Zeitung« 44 (27.4.1848).

Preradović, Petar: Brief an Ivan Kukuljević Sakcinski aus Mailand. In: Građa za povjest kniževnosti hrvatske. Hg. Milivoj Šrepel. Zagreb: JAZU 1897, S. 105-108.

Preradović, Petar: Brief an Ivan Kukuljević Sakcinski vom 29. Februar 1844. In: Građa za povjest kniževnosti hrvatske. Hg. Milivoj Šrepel. Zagreb: JAZU 1897, S. 108-110.

Preradović, Petar: Brief an Ivan Trnski vom 24. November 1861 aus Temeswar. Građa za povjest kniževnosti hrvatske. Hg. Milivoj Šrepel. Zagreb: JAZU 1897, S 186-187.

Preradović, Petar: Brief an Ivan Trnski vom 2. Januar 1870 aus Wien. In: Građa za povjest kniževnosti hrvatske. Hg. Milivoj Šrepel. Zagreb: JAZU 1897, S. 226.

Preradović, Petar: Crtice moga života [1890]. In: Autobiografije hrvatskih pisaca. Hg. Vinko Brešić. Zagreb: AGM 1997, S. 143-149.

Rakovac, Dragutin: Brief an Ljudevit Gaj vom 1. April 1831. In: Pisma pisana Dru. Ĺudevitu Gaju i ńeki ńegovi sastavci (1828-1850). Građa za povijest kniževnosti hrvatske 6. Hg. Velimir Deželić. Zagreb: JAZU 1909, S. 168-170.

Rakovac, Dragutin: Brief an Pavel Josef Šafařík aus Zagreb vom 11. März 1833. In: Građa za povjest kniževnosti hrvatske. Hg. Milivoj Šrepel. Zagreb: JAZU 1897, S. 255.

Rakovac, Dragutin: Mali katekizam za velike ljude/Kleiner Katechismus fuer grosse Leute [1842]. In: Programski spisi hrvatskog narodnog preporoda. Hg. Miroslav Šicel. Zagreb: Matica hrvatska 1997, S. 125-138.

Trnski, Ivan: Brief an Dragojla Jarnević vom 26. Oktober 1939. In: Građa za povjest kniževnosti hrvatske. Hg. Milivoj Šrepel. Zagreb: JAZU 1897, S 178-179.

Veber Tkalčević, Adolf: Brief an Dragojla Jarnević vom 17. November 1854. In: Građa za povjest kniževnosti hrvatske 3. Hg. Milivoj Šrepel. Zagreb: JAZU 1901, S. 219-220.

Vukotinović, Ljudevit: Ilirisam i Kroatisam. In: Programski spisi hrvatskog narodnog preporoda. Hg. Miroslav Šicel. Zagreb: Matica hrvatska 1997, S. 139-146.

Vukotinović, Ljudevit: Offenes Sendschreiben. »Croatia« Jg. II., Nr. 15 (1841), S. 59; Jg. II., Nr. 16 (1841), S. 63; Jg. II., Nr. 17 (1841), S. 66-67; Jg. II., Nr. 19 (1841), S. 74-75; Jg. II, Nr. 20 (1841), S. 77-78.

Vukotinović, Ljudevit: Tri stvari knjiženstva. In: Programski spisi hrvatskog narodnog preporoda. Hg. Miroslav Šicel. Zagreb: Matica hrvatska 1997, S. 147-156.

Vukotinović, Ljudevit: Skizzen über das Slawenthum. »Croatia» Jg. III, Nr. 43 (1842). 
Vukotinović, Ljudevit: Uspomena na godine 1833-35 [1885]. In: Miroslav Šicel: Riznica ilirska 1835-1985. Zagreb, Ljubljana: Nakladni zavod Matice hrvatske, Cankarjeva založba 1985, S. 93-99.

Vukotinović, Ljudevit: Zimske misli [1841-1842]. In: Miroslav Šicel: Riznica ilirska 18351985. Zagreb, Ljubljana: Nakladni zavod Matice hrvatske, Cankarjeva založba 1985.

\section{Forschungsliteratur}

Badalić, Josip: O bilingvizmu u književnosti hrvatskoga preporoda.»Umjetnost riječi. Časopis za nauku o književnosti« 14.1-2 (1979), S. 15-24.

Banac, Ivo: Hrvatsko jezično pitanje. Zagreb: Mladost 1991.

Barac, Antun: Hrvatska književnost od Preporoda do stvaranja Jugoslavije. Knjiga I: Književnost Ilirizma. Zagreb: JAZU 1954.

Batušić, Nikola: Uloga njemačkog kazališta u Zagrebu u hrvatskom kulturnom životu od 1840. do 1860. Zagreb: JAZU 1968.

Blažević, Zrinka: Ilirizam prije ilirizma. Zagreb: Golden marketing - Tehnička knjiga 2008. Bobinac, Marijan: Deutsche Sprache, kroatische Identität. Besprechung von Daniel Barics Langue allemande, identité croate. Au fondement d'un particularisme culturel. Paris 2013. "Zagreber germanistische Beiträge« 22 (2013), S. 111-114.

Brešić, Vinko (Hg.): Autobiografije hrvatskh pisaca. Zagreb: AGM 1997.

Brozović, Dalibor: Povijest hrvatskoga književnog i standardnog jezika. Zagreb: Školska knjiga 2008.

Čizmić-Horvat, Marina: Deutschsprachige Presse in Kroatien. In: Sprachkontakte und Reflexion. »Zagreber germanistische Beiträge« Beiheft 7 (2004), S. 155-162.

Deželić, Velimir: Iz njemačkoga Zagreba. Prinos kulturnoj povijesti Hrvata. Zagreb: Tisak Antuna Scholza 1901.

Deželić, Velimir (Hg.): Pisma pisana Dru. Ĺudevitu Gaju i ńeki ńegovi sastavci (1828-1850); Građa za povijest kniževnosti hrvatske 6. Zagreb: JAZU 1909.

Fishman, Joshua A.: Who Speaks What Language to Whom and When? [1965]. In: The Bilingualism Reader. Hg. Li Wie. Oxford: Routledge 2005, S. 82-98.

Gavrin, Mira: Pjesništvo narodnoga preporoda u odnosu na njemačko i austrijsko pjesništvo. In: Hrvatska književnost prema evropskim književnostima. Hgg. Aleksandar Flaker, Krunoslav Pranjić. Zagreb: Liber, Izdanja Instituta za znanost o književnosti 1970, S. 51-119.

Glovacki-Bernardi, Zrinjka; Hölbling Matković, Lara; Petrušić-Goldstein, Sanja: Agramer - rječnik njemačkih posuđenica u zagrebačkom govoru / Agramer - Wörterbuch der deutschen Lehnwörter in der Stadtsprache von Zagreb. Zagreb: Novi Liber 2013.

Gross, Mirjana: O integraciji hrvatske nacije. In: Društveni razvoj u Hrvatskoj od 16. do početka 20. stoljeća. Hg. dies. Zagreb: Sveučilišna naklada Liber 1981, S. 175-190.

Häusler, Maja: Zur Geschichte des Deutschunterrichts in Kroatien seit dem 18. Jahrhundert. Frankfurt/M.: Peter Lang 1998.

Kessler, Wolfgang: Politik, Kultur und Gesellschaft in Kroatien und Slawonien in der ersten Hälfte des 19. Jahrhunderts. Historiographie und Grundlagen. München: R. Oldenbourg Verlag 1981.

Korunić, Petar: Rasprava o izgradnji moderne hrvatske nacije. Nacija i nacionalni identitet. Slavonski Brod: Hrvatski institut za povijest, Podružnica za povijest Slavonije, Srijema i Baranje 2006. 
Lucius-Hoene, Gabriele; Deppermann, Arnulf: Rekonstruktion narrativer Identität. Ein Arbeitsbuch zur Analyse narrativer Interviews. 2. Aufl. Wiesbaden: VS Verlag für Sozialwissenschaften 2004.

Magaš, Blaženka; Kochansky-Devide, Vanda: Geološka bibliografija SR Hrvatske 1528-1944. Zageb: Hrvatsko geološko društvo 1983.

Markus, Tomislav: Bogoslav Šulek (1816.-1895.) i njegovo doba. Zagreb: Hrvatski institut za povijest 2008 .

Medić, Ivo: Kulturno-historijsko značenje i lingvistička analiza njemačkih pozajmljenica kod zagrebačkih obrtnika. Zagreb: Selbstverl. 1965.

Novak, Kristian: Po rodu, po karvi i po jeziku: Nacionalni identitet u političkim i publicističkim tekstovima Ivana Kukuljevića Sakcinskog. »Povijesni prilozi« 34 (2008), S. 147-174.

Novak, Kristian: Višejezičnost i kolektivni identiteti iliraca. Jezične biografije Dragojle Jarnević, Ljudevita Gaja i Ivana Kukuljevića Sakcinskog. Zagreb: Srednja Europa 2012.

Piškorec, Velimir: Deutsches Lehngut in der kajkavisch-kroatischen Mundart von Đurdevec in Kroatien. Frankfurt/M.: Peter Lang 1997.

Piškorec, Velimir: Germanizmi u govorima durđevečke Podravine. Zagreb: FF-press 2005.

Riehl, Claudia Maria: Sprachkontaktforschung. Eine Einführung. Tübingen: Gunter Narr Verlag 2004.

Rutz, Andreas: Ego-Dokument oder Ich-Konstruktion? Selbstzeugnisse als Quellen zur Erforschung des frühneuzeitlichen Menschen. »zeitenblicke» 1.2 (2002). <http://www. zeitenblicke.historicum.net/2002/02/rutz/index.html> (Zugriff: 20.5.2015).

Sikirić Assouline, Zvjezdana: Latinitet u hrvatskom društvu prve polovice 19. stoljeća. »Radovi Zavoda za hrvatsku povijest « 41 (2009), S. 257-265.

Stančić, Mirjana: Verschüttete Literatur. Die deutschsprachige Dichtung auf dem Gebiet des ehemaligen Jugoslawien von 1800 bis 1945. Wien, Köln, Weimar: Böhlau Verlag 2013.

Stančić, Nikša: Hrvatski narodni preporod 1790-1848. In: Hrvatski narodni preporod 1790-1848. Hrvatska u vrijeme Ilirskoga pokreta. Hg. ders. Zagreb: Muzej za umjetnost i obrt 1985, S. 1-30.

Stančić, Nikša: Hrvatska nacija i nacionalizam u 19. i 20. stoljeću. Zagreb: Barbat 2002.

Šicel, Miroslav: Riznica ilirska 1835-1985. Zagreb, Ljubljana: Nakladni zavod Matice hrvatske, Cankarjeva založba 1985.

Šicel, Miroslav (Hg.): Programski spisi hrvatskog narodnog preporoda. Zagreb: Matica hrvatska 1997.

Šidak, Jaroslav; Foretić, Vinko; Grabovac, Julije; Karaman, Igor; Strčić, Petar; Valentić, Mirko: Hrvatski narodni preporod - ilirski pokret. Zagreb: Školska knjiga - Stvarnost 1990.

Škiljan, Dubravko: Govor nacije. Jezik, nacija, Hrvati. Zagreb: Golden marketing 2002.

Škreb, Zdenko: Preradovićeva pisma Emi Regnerovoj. In: Građa za povijest književnosti hrvatske 22. Hg. Antun Barac. Zagreb: JAZU 1952, S. 7-146.

Šrepel, Milivoj (Hg.): Građa za povjest kniževnosti hrvatske. Zagreb: JAZU 1897.

Šrepel, Milivoj: Molba V. Lisinskoga upravlena banu Jelačiću. In: Građa za povijest kniževnosti hrvatske 4. Hgg. August Musić, Milivoj Šrepel. Zagreb: JAZU 1904.

Švoger, Vlasta: Zagrebački liberalni tisak o preobrazbi hrvatskoga gospodarstva i izgradnji modernoga kapitalističkoga gospodarskog sustava 1848.-1852. »Povijesni prilozi« 28 (2005), S. 173-197.

Tabouret-Keller, Andree: Language and Identity. In: The Handbook of Sociolinguistics. Hg. Florian Coulmas. Oxford: Blackwell Publishers Ltd. 1997, S. 315-326.

Tafra, Branka: Značenje narodnoga preporoda za hrvatski jezik. »Croatica et Slavica Iadertina« II (2006), S. 43-55. 
Turković, Slađan: Deutsche Lehnwörter in der Fachsprache der Zagreber Handwerker. »Zagreber Germanistische Beiträge 6 (1997), S. 131-155.

Van Dijk, Teun A.: Discourse and Context. A Sociocognitive Approach. Cambridge: Cambridge University Press 2008.

Žepić, Stanko: Zur Geschichte der deutschen Sprache in Kroatien. »Zagreber Germanistische Beiträge« 11 (2002), S. 209-227. 